\title{
Mobility and self-righting by a free-living mushroom coral through pulsed inflation
}

\author{
Bert W. Hoeksema $^{1,2} \cdot$ Pim Bongaerts ${ }^{3}$
}

Received: 23 March 2015 /Revised: 9 August 2015 / Accepted: 11 August 2015 / Published online: 11 September 2015

(C) The Author(s) 2015. This article is published with open access at Springerlink.com

\begin{abstract}
Locomotion and self-righting in an overturned juvenile mushroom coral, Herpolitha limax, was documented and analyzed by the use of time-lapse photography. The coral used a series of rhythmic polyp expansions and contractions to move itself. The complete process of the righting took place within six hours, consisting of a stationary phase, a shuffle phase, a sudden flip-over, and a recovery phase. The mouth of the coral may be used to eject water, which can perhaps be applied as a means of jet propulsion. This report demonstrates that time-lapse photography can be applied to analyze all kinds of behavior in marine invertebrates that move too slow for regular observations.
\end{abstract}

Key words Behavior · Flip-over · Hopping $\cdot$ Jet propulsion · Locomotion $\cdot$ Overturning $\cdot$ Shuffle phase $\cdot$ Time-lapse photography

Communicated by P. Martinez Arbizu

Electronic supplementary material The online version of this article (doi:10.1007/s12526-015-0384-y) contains supplementary material, which is available to authorized users.

Bert W. Hoeksema

bert.hoeksema@naturalis.nl

Pim Bongaerts

pim@uq.edu.au

1 Department of Marine Zoology, Naturalis Biodiversity Center, P.O. Box 9517, 2300, RA Leiden, The Netherlands

2 Institute of Biology Leiden, Leiden University, P.O. Box 9505, 2300, RA Leiden, The Netherlands

3 Global Change Institute, The University of Queensland, QLD 4072 St Lucia, Australia

\section{Introduction}

More than $70 \%(\mathrm{n}=55)$ of all recent mushroom coral species (Scleractinia: Fungiidae) have a free-living adult phase in their life history (Gittenberger et al. 2011; Benzoni et al. 2012), which is the so-called anthocyathus stage (Wells 1966; Hoeksema 1989). Only as juveniles in the anthocaulus stage, free-living fungiids are still attached to a solid substratum by a stalk, regardless of whether they have a single mouth or more than one (Hoeksema and Gittenberger 2010; Hoeksema and Benzoni 2013). Subsequent detachment takes place in the upper part of the stalk by dissolution of the calcareous skeleton across a distinct plane just below the polyp disc (Yamashiro and Yamazato 1996). After detachment, initially a scar remains visible on the aboral side of the polyp disc (Vizel et al. 2009; Hoeksema and Yeemin 2011).

As free-living corals, fungiids are able to colonize all kinds of substrata. These include sandy bottoms at $>20 \mathrm{~m}$ depth, which are usually not inhabited by many other bottom organisms and where mushroom corals can form dense aggregations (Goreau and Yonge 1968; Fisk 1983; Hoeksema 2012). They may also inhabit reef slopes where they can dominate over other benthic organisms (Goffredo and Chadwick-Furman 2000; Hoeksema and Matthews 2011; Hoeksema and Benzoni 2013). Free-living fungiids may use their mobility in densely inhabited habitats to escape from harmful interactions, or they may aggressively damage competitors (Chadwick 1988; Chadwick-Furman and Loya 1992; Hoeksema and De Voogd 2012; Hoeksema et al. 2014). The flip side of a free mode of life is that mushroom corals may accidentally get overturned by other animals or by tumbling down-slope (Jokiel and Cowdin 1976; Hoeksema 1988; Chadwick-Furman and Loya 1992). This is unfavorable because it would incapacitate their ability to capture food, for which an upright position would be most suitable (Hoeksema and Waheed 2012; Mehrotra et al. 2015). 
Although it is known that mushroom corals may undergo sessile dispersal by their migration over the seafloor (Hoeksema 1988; Nishihira and Poung-In 1989; Gittenberger and Hoeksema 2013), only few reports are known concerning active mobility resulting from their own movements (Abe 1939; Horridge 1957; Hubbard 1972; Jokiel and Cowdin 1976; Yamashiro and Nishihira 1995). In the present report, we present detailed information on a flip-over experiment in which mushroom corals were overturned to document their self-righting technique with the help of time-lapse photography.

\section{Materials and methods}

Three specimens of three mushroom coral species were collected from the reef of Heron Island (Great Barrier Reef, Australia): the elongate, polystomatous Herpolitha limax (Esper, 1797), the oval-shaped, monostomatous Lobactis scutaria (Lamarck, 1801), and the disk-shaped, monostomatous Pleuractis granulosa (Klunzinger, 1879). First, they were kept in seawater basins with flowing seawater at Heron Island Research Station in normal daylight regime. For the duration of the experiment, they were brought to a laboratory and placed upside-down on a substrate consisting of coarse sand inside a self-contained aquarium. This tank is a commercially available Dymax ${ }^{\circledR}$ IQ5 Mini Acryclic Aquarium (Coburg, Australia) with a built-in filtration system and a 43 dual colour LED lamp burning continuously during the experiment. The tank contained 131 of seawater $\left(25^{\circ} \mathrm{C}\right)$ and its bottom measures $27 \times 22 \mathrm{~cm}^{2}$.

Coral movements were documented by use of time-lapse photography (Bongaerts et al. 2012). The corals had their tentacles expanded and showed rhythmic pulses of inflation and exhalation, and slightly shifted their position, but the specimens of $L$. scutaria and P. granulosa, were not able to turn over within an available time frame of $10 \mathrm{~h}$.

One small individual of $\sim 7 \mathrm{~cm}$ in length of $H$. limax, with a relatively large primary mouth and three small secondary mouths aligned along its main axis, managed to overturn itself within only $6 \mathrm{~h}$. The process of this flip-over is described and discussed by showing still shots extracted from a $900 \times$ timelapse movie (see ESM). A second sequence of movements ( 2 h 15 min long) without overturning has been filmed to obtain additional information on the pulse frequency, which was measured as the mean time interval between two pulses, visible as shuffles and hops.

\section{Results}

The complete flip-over process consisted of four phases, which took less than $6 \mathrm{~h}$ to complete: (1) a stationary phase of $\sim 1 \mathrm{~h}$ in which the coral only waved its tentacles (Fig. 1a); (2) a shuffle
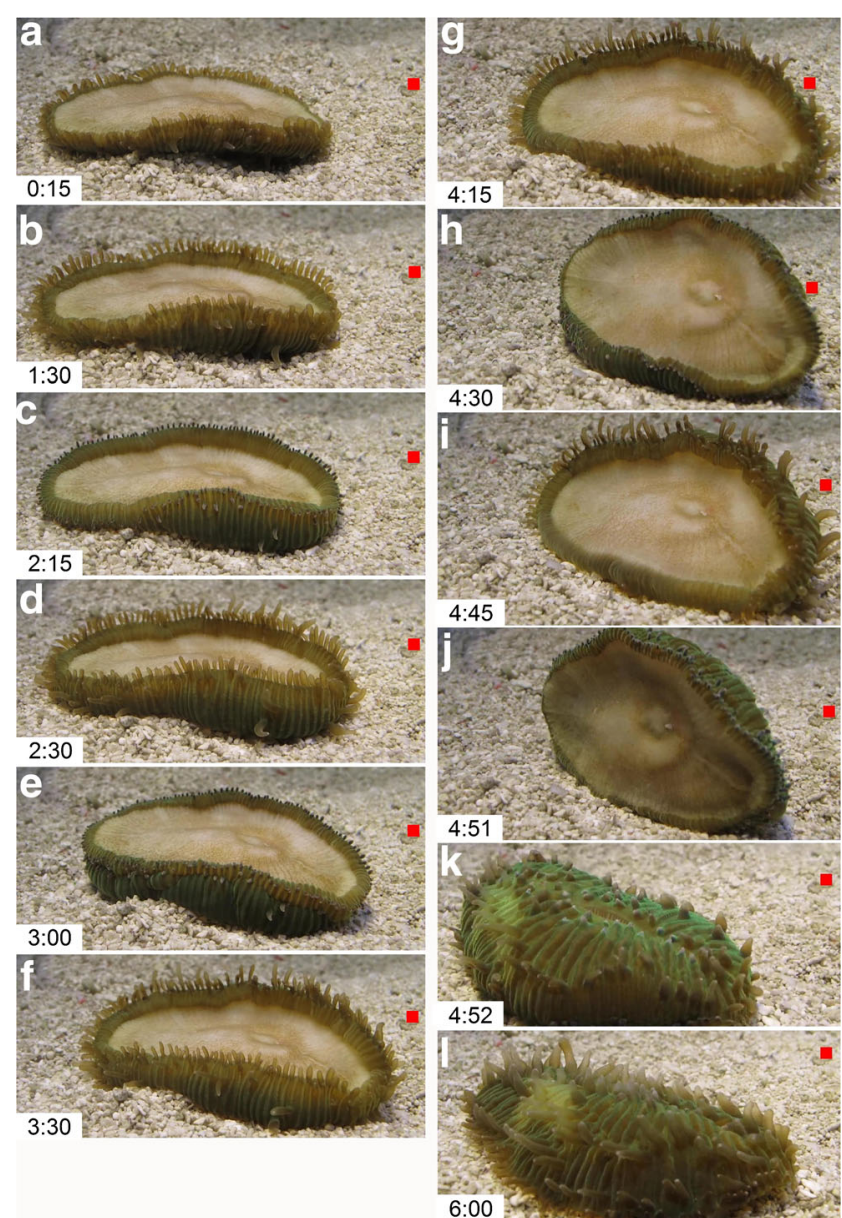

Fig. 1 Still shots from time-lapse video (6 h long) showing cycles of tissue inflation and deflation in a Herpolitha limax specimen (length $\sim 7$ $\mathrm{cm}$ ) after being overturned: a stationary phase, $\mathbf{b}$-f shuffling and hopping, $\mathbf{g}$-i turning phase, $\mathbf{j}$ flip-over, $\mathbf{k}-\mathbf{l}$ recovery. Time moments are indicated in hours and minutes, h:min). Red square: reference point

phase ( $3 \mathrm{~h} 15 \mathrm{~min}$ long), in which the coral hopped and shifted 11 times over the sand with the oral side remaining close to the bottom and occasionally appearing to become detached from it, and with increasing force (Fig. 1b-f); (3) the flip-over phase, in which the oral side became lifted away from the sand by the coral turning over its side (Fig. 1g-i), which was concluded by a sudden flip-over at 4:51 h (Fig. 1j); and (4) the subsequent recovery phase (Fig. 1k-1). During the second movie, only part of a shuffle phase was recorded.

The mean time interval between two jumps as registered in both film shots together was $22.5 \mathrm{~min}$ (s.d. $7.9 \mathrm{~min}, n=17$ ). After every inflation the aboral side became lifted upward and sank down again, resembling hopping, with increasing amplitude but without a clear change in frequency. The body mass swelled up and curled somewhat around the exposed aboral side while the tentacles expanded and retracted. During the turning, one side gradually rose more than the other and one flip-over attempt failed to be completed (Fig. 1i). During the second try, the coral succeeded (Fig. 1j). At the start of the recovery the mouth was open (Fig. 1k), suggesting that water 
had been ejected from it. Eventually, the coral polyp became deflated and shrank (Fig. 11).

\section{Discussion}

This is the first time that self-righting in free-living corals is documented, analysed and published with the help of timelapse photography. Abe (1939) used a kimograph and direct observations to study the righting in Heliofungia actiniformis (Quoy and Gaimard, 1833), a mushroom coral species with a large, fleshy polyp and long tentacles. According to him the mouth of the coral opened just after the flip-over while it was shut during the move itself. Hubbard (1972) studied selfrighting in a small mushroom coral species, Cycloseris distorta Michelin, 1842, and observed that it is able to use jet propulsion before the final flip-over. The mushroom coral of the video movie had its primary mouth open just after landing (Fig. 1k). This suggests that it was used for jet propulsion during the flip-over, which could not be seen because the oral side was directed downward and away from the camera.

Previously, time-lapse photography in laboratory conditions was applied to study sediment shedding in a mushroom coral (Bongaerts et al. 2012). This method was also used to study locomotion in Cycloseris distorta, which showed that this mushroom coral uses peristaltic movements to crawl toward light (Yamashiro and Nishihira 1995). Besides mushroom corals, righting and migration have also been observed in other free-living corals, such as in the Caribbean Manicina areolata (Linnaeus, 1758) (see Fabricius 1964; Hubman et al. 2002; Uhrin et al. 2005) and the Indo-Pacific Heteropsammia cochlea (Spengler, 1781) (see Goreau and Yonge 1968). The latter studies were based on field studies.

Righting in free-living corals may take much time and can, therefore, be difficult to observe. It has to be stressed that the present observations concern a single small, coral individual. All observed corals, regardless of their species identity, showed similar behavior (see also Hubbard 1972). Duration of the hopping intervals and the entire flip-over process is expected to vary among individual corals because mushroom corals of some species are more frequently found in upsidedown position than those of others, which may depend on their weight, size, and shape, as well as depth, substrate type, and steepness of the reef slope (Hoeksema 1988; Gittenberger and Hoeksema 2013; Mondal and Raghunathan 2015). The largest and heaviest free-living corals are probably the least acrobatic.

An elongated corallum shape and a low coral weight as in the present specimen may have helped to complete this observation. Both corals that did not manage to right themselves within the available filming time, may have been too heavy (in the case of Lobactis scutaria) or not slender enough for a sideways flipover (in the case of Pleuractis granulosa). Many mushroom corals are round and may indeed become large and heavy (Hoeksema 1991). Such corals can probably become displaced during storms (Hoeksema 1988), after which they can still free themselves from sediment by the use of pulsed body inflation (Bongaerts et al. 2012).

Earlier observations (Yamashiro and Nishihira 1995; Bond 2013) and the present results show that lime-lapse photography can be of much help in observing mobility of corals and other invertebrates. In future studies, all kinds of free-living coral species can be studied in this way, such as the West Atlantic species Manicina areolota (Linnaeus, 1758) and Meandrina danae (Milne Edwards and Haime, 1848) (Johnson 1988; Meesters et al. 2012), and the Indo-Pacific Heteropsammia spp. and Heterocyathus spp. (Goreau and Yonge 1968; Hoeksema and Best 1991; Hoeksema and Matthews 2015). The latter species are famous for their symbiosis with a sipunculan worm, which slowly pulls the corals over the seafloor. Time-lapse photography may be able to show what kind of behavior is performed by such free-living corals when they are placed in various densities and on different kinds of substrates.

Acknowledgments We want thank two anonymous reviewers for their supportive and constructive comments.

Open Access This article is distributed under the terms of the Creative Commons Attribution 4.0 International License (http:// creativecommons.org/licenses/by/4.0/), which permits unrestricted use, distribution, and reproduction in any medium, provided you give appropriate credit to the original author(s) and the source, provide a link to the Creative Commons license, and indicate if changes were made.

\section{References}

Abe N (1939) Migration and righting reaction of the coral Fungia actiniformis var. palawensis Döderlein. Palao Trop Biol Sta Stud 4:671-694

Benzoni F, Arrigoni R, Stefani F, Reijnen BT, Montano S, Hoeksema BW (2012) Phylogenetic position and taxonomy of Cycloseris explanulata and $C$. wellsi (Scleractinia: Fungiidae): lost mushroom corals find their way home. Contrib Zool 81:125-146

Bond C (2013) Locomotion and contraction in an asconoid calcareous sponge. Invertebr Biol 132:283-290

Bongaerts P, Hoeksema BW, Hay KB, Hoegh-Guldberg O (2012) Mushroom corals overcome live burial through pulsed inflation. Coral Reefs 31:399

Chadwick NE (1988) Competition and locomotion in a freeliving fungiid coral. J Exp Mar Biol Ecol 123:189-200

Chadwick-Furman NE, Loya Y (1992) Migration, habitat use, and competition among mobile corals (Scleractinia: Fungiidae) in the Gulf of Eilat, Red Sea. Mar Biol 114:617-623

Fabricius F (1964) Active Lage- und Ortveränderung bei der Koloniekoralle Manicina areolata und ihre paläoökologische Bedeutung. Senckenb Lethaea 45:299-323 
Fisk DA (1983) Free-living corals: distributions according to plant cover, sediments, hydrodynamics, depth and biological factors. Mar Biol 74:287-294

Gittenberger A, Hoeksema BW (2013) Habitat preferences of coralassociated wentletrap snails (Gastropoda: Epitoniidae). Contrib Zool 82:1-25

Gittenberger A, Reijnen BT, Hoeksema BW (2011) A molecularly based phylogeny reconstruction of mushroom corals (Scleractinia: Fungiidae) with taxonomic consequences and evolutionary implications for growth forms and life history traits. Contrib Zool 80:107132

Goffredo S, Chadwick-Furman NE (2000) Abundance and distribution of mushroom corals (Scleractinia: Fungiidae) on a coral reef at Eilat, northern Red Sea. Bull Mar Sci 66:241-254

Goreau TF, Yonge CM (1968) Coral community on muddy sand. Nature 217:421-423

Hoeksema BW (1988) Mobility of free-living fungiid corals (Scleractinia) a dispersion mechanism and survival strategy in dynamic reef habitats. Proc 6th Int Coral Reef Symp 2:715-720

Hoeksema BW (1989) Taxonomy, phylogeny and biogeography of mushroom corals (Scleractinia: Fungiidae). Zool Verh 254:1-295

Hoeksema BW (1991) Evolution of body size in mushroom corals (Scleractinia: Fungiidae) and its ecomorphological consequences. Neth J Zool 41:122-139

Hoeksema BW (2012) Distribution patterns of mushroom corals (Scleractinia: Fungiidae) across the Spermonde Shelf, South Sulawesi. Raffles Bull Zool 60:183-212

Hoeksema BW, Benzoni F (2013) Multispecies aggregations of mushroom corals in the Gambier Islands, French Polynesia. Coral Reefs 32:1041

Hoeksema BW, Best MB (1991) New observations on scleractinian corals from Indonesia: 2. Sipunculan-associated species belonging to the genera Heterocyathus and Heteropsammia. Zool Meded 65:221-245

Hoeksema BW, de Voogd NJ (2012) On the run: free-living mushroom corals avoiding interaction with sponges. Coral Reefs 31:455-459

Hoeksema BW, Gittenberger A (2010) High densities of mushroom coral fragments at West Halmahera, Indonesia. Coral Reefs 29:691

Hoeksema BW, Matthews JL (2011) Contrasting bleaching patterns in mushroom coral assemblages at Koh Tao, Gulf of Thailand. Coral Reefs 30:95

Hoeksema BW, Matthews JL (2015) Partial bleaching in an assemblage of small apozooxanthellate corals of the genera Heteropsammia and Heterocyathus. Coral Reefs. doi:10.1007/s00338-015-1314-y
Hoeksema BW, Waheed Z (2012) It pays to have a big mouth: mushroom corals ingesting salps at northwest Borneo. Mar Biodiv 42:297-302

Hoeksema BW, Yeemin T (2011) Late detachment conceals serial budding by the free-living coral Fungia fungites in the Inner Gulf of Thailand. Coral Reefs 30:975

Hoeksema BW, Dekker F, de Voogd NJ (2014) Free-living mushroom corals strike back by overtopping a coral-killing sponge. Mar Biodiv 44:3-4

Horridge GA (1957) The co-ordination of the protective retraction of coral polyps. Phil Trans R Soc Lond B 240:495-528

Hubbard JAEB (1972) Diaseris distorta, an "acrobatic" coral. Nature 236:457-459

Hubman B, Piller WE, Riegl B (2002) Functional morphology of coral shape and passive hydrodynamic self-righting in Recent Manicina areolata. Senckenb Lethaea 82:125-130

Johnson KG (1988) Size, meander pattern, and behavior in the Caribbean free-living meandroid coral Manicina areolata (Linnaeus). Proc 6th Int Coral Reef Symp 3:403-408

Jokiel PL, Cowdin HP (1976) Hydromechanical adaptation in the solitary free-living coral Fungia scuturia. Nature 262:212-213

Meesters EH, Mueller B, Nugues MM (2012) Caribbean free-living coral species co-occurring deep off the windward coast of Curaçao. Coral Reefs 32:109

Mehrotra R, Scott CM, Rohrer JM, Hoeksema BW (2015) Predation on a sacoglossan gastropod by a mushroom coral. Coral Reefs 34:517

Mondal T, Raghunathan C (2015) Locomotion of anthocyathus mushroom corals (Scleractinia: Fungiidae) of Andaman and Nicobar Islands, India. Indian J Mar Sci 44(6): 12, 7 pp

Nishihira M, Poung-In S (1989) Distribution and population structure of a free-living coral, Diaseris fragilis, at Khang Khao Island in the Gulf of Thailand. Galaxea 8:271-282

Uhrin AV, Slade CL, Holmquist JF (2005) Self righting in the free-living coral Manicina areolata (Cnidaria: Scleractinia): morphological constraints. Caribb J Sci 40:277-282

Vizel M, Kramarsky-Winter E, Loya Y (2009) Mushroom coral regeneration from a detached stalk. Coral Reefs 28:939

Wells JW (1966) Evolutionary development in the scleractinian family Fungiidae. Symp Zool Soc Lond 16:223-246

Yamashiro H, Nishihira M (1995) Phototaxis in Fungiidae corals (Scleractinia). Mar Biol 124:461-465

Yamashiro H, Yamazato K (1996) Morphological studies of the soft tissues involved in skeletal dissolution in the coral Fungia fungites. Coral Reefs 15:177-180 